\title{
"If You Want Me to Treat You Like an Adult, Start Acting Like One!" Comparing the Criteria That Emerging Adults and Their Parents Have for Adulthood
}

\author{
Larry J. Nelson \\ Laura M. Padilla-Walker \\ Brigham Young University - Provo \\ Jason S. Carroll \\ Brigham Young University - Provo, jcarroll@byu.edu \\ Stephanie D. Madsen \\ K9lleakt 枹isand additional works at: https://scholarsarchive.byu.edu/facpub \\ Part of the Other Social and Behavioral Sciences Commons \\ Carolyn McNamara Barry \\ Loyola College in Maryland \\ Original Publication Citation \\ Nelson, L. J., Padilla-Walker, L. M., Carroll, J. S., Madsen, S. D., Barry, C., \& Badger, S.* (2007). "If \\ Sou wextpage for treatitjonal liketharsadult start acting like one!"-Comparing the Criteria for \\ Adulthood Among Emerging Adults and Their Parents. Journal of Family Psychology, 21, \\ 665-674.
}

\section{BYU ScholarsArchive Citation}

Nelson, Larry J.; Padilla-Walker, Laura M.; Carroll, Jason S.; Madsen, Stephanie D.; Barry, Carolyn McNamara; and Badger, Sarah, "'If You Want Me to Treat You Like an Adult, Start Acting Like One!" Comparing the Criteria That Emerging Adults and Their Parents Have for Adulthood" (2007). Faculty Publications. 4338.

https://scholarsarchive.byu.edu/facpub/4338

This Peer-Reviewed Article is brought to you for free and open access by BYU ScholarsArchive. It has been accepted for inclusion in Faculty Publications by an authorized administrator of BYU ScholarsArchive. For more information, please contact ellen_amatangelo@byu.edu. 


\section{Authors}

Larry J. Nelson, Laura M. Padilla-Walker, Jason S. Carroll, Stephanie D. Madsen, Carolyn McNamara Barry, and Sarah Badger

This peer-reviewed article is available at BYU ScholarsArchive: https://scholarsarchive.byu.edu/facpub/4338 


\title{
"If You Want Me to Treat You Like an Adult, Start Acting Like One!" Comparing the Criteria That Emerging Adults and Their Parents Have for Adulthood
}

\author{
Larry J. Nelson, Laura M. Padilla-Walker, and \\ Jason S. Carroll \\ Brigham Young University \\ Carolyn McNamara Barry \\ Loyola College in Maryland
}

\author{
Stephanie D. Madsen \\ McDaniel College \\ Sarah Badger \\ Brigham Young University
}

\begin{abstract}
The purpose of this study was (a) to identify the criteria parents of emerging adults consider necessary and important for their children to achieve adulthood, (b) to compare parents' criteria for adulthood with the criteria espoused by emerging adults, and (c) to examine how these criteria might differ on the basis of gender of the parent and gender of the child. Participants included 392 unmarried college students, ages 18-25, and at least 1 of their parents (271 fathers, 319 mothers). Results revealed that (a) as did their children, most parents did not yet view their children as adults, (b) there was disagreement between children and their parents in the emphasis they placed on various criteria for adulthood, (c) mothers and fathers did not always agree on the importance of various criteria, and (d) the gender of both the parent and the child played a role in the criteria parents deemed important for adulthood. Taken together, the findings suggest that parents and children view the transition to adulthood differently, which might have implications for the parent-child relationship during this period of development.
\end{abstract}

Keywords: emerging adulthood, parent-child relationships, transition to adulthood, criteria for adulthood

Recent research has shown that the majority of 18-25year-olds in the United States do not consider themselves to be adults. Specifically, studies consisting mainly of college student samples have consistently shown that only about $25 \%$ of young people consider themselves to be adults (e.g., Arnett, 1994; Badger, Nelson, \& Barry, 2006; Nelson \& Barry, 2005). Given the ambivalence many young people feel about their status as adults at this age, this period of time has been referred to with terms such as arrested adulthood (Côté, 2000), youth (Keniston, 1971), and emerging adulthood (Arnett, 2000, 2006). For many of these emerging adults (as they hereafter will be called), it is

Larry J. Nelson, Laura M. Padilla-Walker, Jason S. Carroll, and Sarah Badger, School of Family Life, Brigham Young University; Stephanie D. Madsen, Department of Psychology, McDaniel College; Carolyn McNamara Barry, Department of Psychology, Loyola College in Maryland.

We express appreciation to the instructors and students at all Project READY data collection sites for their assistance. We also are grateful for the grant support of the Family Studies Center at Brigham Young University as well as grant support from Loyola College in Maryland.

Correspondence concerning this article should be addressed to Larry J. Nelson, 2091 JFSB, School of Family Life, Brigham Young University, Provo, UT 84602. E-mail: larry_nelson@byu.edu becoming increasingly clear that the pathway to adulthood is not clearly defined, nor does the transition happen quickly. Many emerging adults are well into their mid- to late 20 s before they settle into adult roles and responsibilities. Given the ambivalence that young people feel, it would seem probable that parents are equally confused as to how to view this period of life. However, little work has been done to examine the expectations parents have for their children during this time. Thus, the purpose of this study was threefold: first, to identify the criteria parents of emerging adults consider necessary and important for their children to achieve adulthood; second, to compare parents' criteria for adulthood with the criteria espoused by emerging adults; and third, to examine how these criteria might differ on the basis of gender of both the child and parent.

\section{Theory of Emerging Adulthood}

With a few notable exceptions (e.g., Bockneck, 1986; Erikson, 1968; Keniston, 1971), little has been done theoretically to set a framework for studying development immediately following adolescence. Even most of these exceptions are decades old and therefore do not capture the life experiences of today's young people. In order to address this theoretical gap, Arnett $(2000,2006)$ proposed a theory of emerging adulthood which attempts to conceptualize the 
development of young people ages 18-25 in Western, industrialized societies. He proposes that there are distinct features of this time period that set it apart as a unique period of development in the life course, including identity exploration (especially in the areas of work, love and world views), instability (seen in changes of direction in residential status, relationships, work, and education), focus on the self (not self-centered but simply lacking obligations to others such as spouse or children), feeling in-between (do not see themselves as either adolescents or adults), and possibilities (potential to steer their lives in any number of desired directions). These five conceptual features can be seen in the behavior of emerging adults. For example, emerging adults are entering into increasingly intimate nonmarital relationships and are engaging in relatively high rates of risky behaviors such as unprotected intercourse, illegal drug use, and driving while drunk (see Arnett, 2000).

\section{Criteria for Adulthood}

Because of the mixed views many young people have regarding their adult status (i.e., "in-between-ness" that is a feature of this period), there has been marked interest in recent years in the criteria emerging adults perceive as necessary for adulthood. Initial studies in this area (e.g., Arnett, 1998; Nelson \& Barry, 2005) have documented that the criteria contemporary emerging adults tend to view as being necessary for adulthood center around (a) being independent and self-reliant (e.g., accepting responsibility for the consequences of one's actions, becoming financially independent of parents), (b) being able to form mature relationships (e.g., becoming less self-oriented and developing greater consideration for others), (c) being able to comply with societal norms (e.g., avoiding drunk driving and committing petty crimes), and (d) being able to provide and care for a family (e.g., becoming capable of caring for children). These criteria have been identified across a variety of cultures (e.g., Israel: Mayseless \& Scharf, 2003; China: Nelson, Badger, \& Wu, 2004; Argentina: Facio \& Micocci, 2003; Aboriginal Canadians: Cheah \& Nelson, 2004) as well as ethnic (Arnett, 2003) and religious (Nelson, 2003; Barry \& Nelson, 2005) subgroups within the United States. These studies have also shown that there is widespread consensus among emerging adults that traditional markers of adulthood, such as getting married, becoming a parent, or purchasing a home, are not seen as necessary aspects of becoming an adult in today's society.

\section{Parental Criteria for Adulthood}

Although scholars have a growing understanding of the criteria young people deem necessary for adulthood, less is known regarding adults' views of these criteria. Bangerter, Grob, and Krings (2001) asked three different cohorts (ages 25,50 , and 75) what their personal goals were at age 25 , but the two older cohorts were not asked about what they felt the goals for young people today should be, nor were they specifically asked about criteria for adulthood. In another notable study, Arnett (2001) compared the criteria of teen- agers, individuals ages 20-29, and young-to-midlife adults ages 30-55. However, no attempt was made to specifically identify parents of emerging adults. In another study conducted in Israel, Mayseless and Scharf (2003) examined the criteria that parents of adolescents endorsed as necessary for adulthood. In both of these studies, the adults, like the emerging adults, tended to endorse criteria related to being an independent individual (e.g., accepting responsibility for one's actions and deciding on one's beliefs and values). However, no research of which we are aware has examined the criteria that parents of emerging adults endorse as necessary to consider their children to be adults nor how these perceived criteria may differ based on the gender of the parent or gender of the child.

How criteria for adulthood differ as a function of gender is particularly important given research suggesting that the gender of both the parent and the child impacts the quality of parent-child interactions (Fagot, 1995). From birth, parents tend to relate differently to children and hold different expectations for them on the basis of gender (Lamb, Hwang, Ketterlinus, \& Fracasso, 1999). For example, parents tend to be more protective of daughters than sons (Maccoby, 1995), and overall, mothers tend to have closer relationships with their children than do fathers (Hosley \& Montemayor, 1997). Given the impact that gender has on the quality of the parent-child relationship, the gender of both the parent and the child should be taken into account when examining differences in criteria for adulthood between parents and children.

Another limitation of past research includes the way in which criteria have been measured. Much of the recent work has been based on Arnett's (e.g., 2003) conceptual domains of independence, interdependence, role transitions, norm compliance, family capacities, biological transitions, and chronological transitions. The problem with these conceptual domains is that although they have demonstrated face validity, they have not held up to statistical tests of reliability. For example, studies using Arnett's independence and interdependence subscales have consistently reported low reliability coefficients. Alpha levels for the independence subscale have been reported as low as .42 (Arnett, 2003) and .53 (Nelson \& Barry, 2005). In an effort to address this problem, Badger, Nelson, and Barry (2006) used confirmatory factor analysis to identify an alternative model that would demonstrate statistical reliability in two cultures (China and the United States). The resulting model, which demonstrated good fit indices, included a scale that was a combination of Arnett's independence and interdependence scales. It was labeled relational maturity and included such items as "accept responsibility for the consequences of your actions," and "become less self-oriented, develop greater consideration for others." Badger et al. argued that relational maturity reflects the value of social responsibility, suggesting that by increasing one's ability to monitor oneself and to control one's impulses, the individual is considering the needs and desires of others. On the basis of both its conceptual strength and greater internal consistency, we felt it important to examine the criteria young people and their parents have for adulthood using this new domain. 


\section{Hypotheses}

Taken together, a greater understanding of parents' criteria for adulthood is potentially important for a number of reasons. First, this type of examination would provide insight into how criteria for adulthood differ between generations or across the lifespan (e.g., an individual views the world differently as a parent than as a child). Second, and perhaps more important, understanding parental beliefs and expectations for their children may provide insights into parent-child interactions during emerging adulthood and help explain differences in parent-child relationships across these years. Therefore, the purpose of this study was to assess whether parents considered their 18- to 25-year-old children to be adults and to examine the criteria parents, compared with their children, considered necessary and important for their children to achieve adulthood. Furthermore, differences based on both child gender and parent gender were examined.

Given that no previous research has examined the criteria parents hold as necessary for their children to be considered adults, there is little empirical basis for hypotheses. However, building upon the features of this time period proposed in Arnett's theory of emerging adulthood, several expectations may be formulated. First, past research has found that young people who are striving towards becoming their own person (i.e., identity exploration, particularly in the area of love and relationships, etc.) place great importance on areas that include aspects of independence and relationship formation (i.e., relational maturity; Badger et al., 2006; Nelson \& Barry, 2005). On the other hand, it is possible that parents, responding to the high levels of risk behaviors that mark this time period, would be more focused on helping their children prepare for responsibilities (e.g., complying with societal norms). Furthermore, parents (especially mothers, given their ethic of caring; Gilligan, 1982) may better understand what adulthood entails, so they might place less emphasis on specific events (e.g., marriage, finishing education, having intercourse) than their children and more on skills and abilities that are necessary to form and maintain relationships (e.g., relational maturity, including other-oriented characteristics such as becoming less focused on self; ability to care for a family) and that involve overall maturity (e.g., avoiding risk behaviors). Therefore, it was expected that emerging adults would place greater importance on criteria related to specific role transitions and biological transitions, whereas parents would rate as more important the criteria related to norm compliance and family capacities.

In regard to gender, previous research has found that emerging-adult women tend to place greater importance on norm compliance and family capacities than do men (e.g., Barry \& Nelson, 2005; Cheah \& Nelson, 2004). Therefore, similar findings were expected in the present study. In regard to gender and parental criteria for adulthood, the dearth of research examining parenting during emerging adulthood made it difficult to make specific hypotheses. However, on the basis of existing research suggesting the importance of considering gender when examining the parent-child relationship (Fagot, 1995; Lamb et al., 1999), we explored the potential differences in criteria for adulthood as a function of gender of the parent and gender of the child.

\section{Method}

\section{Participants}

Participants were drawn from an ongoing study of emerging adults and their parents titled Project READY (Researching Emerging Adults Developmental Years). From an original sample of 802 unmarried undergraduate and graduate students, emerging adults who had at least one parent agree to participate were selected for the current study $(N=$ $392, M_{\mathrm{age}}=19.89, S D=1.78$, range $\left.=18-25\right)$. Parents included 271 fathers $\left(M_{\text {age }}=51.24, S D=5.39\right.$, range $=$ 36-72) and 319 mothers $\left(M_{\text {age }}=48.96, S D=4.32\right.$, range $=38-64)$. Students were recruited from a small liberal arts college in the mid-Atlantic $(n=57)$, a mediumsized religious university in the mid-Atlantic $(n=204)$, two large midwestern public universities $(n=83)$, and a large public university on the West Coast $(n=48)$. The emerging adult sample was predominantly female (242 females vs. 150 males) and of European American ethnicity (84\% European American, 4\% African American, 6\% Asian American, 3\% Latino American, 3\% indicated that they were mixed, biracial, or an "other" ethnicity).

\section{Procedure}

With the approval of the internal review board for each participating university, data were collected using selfreport instruments administered via the Internet (see http:// www.projectready.net). The use of an online data collection protocol facilitated unified data collection across multiple university sites and allowed for the survey to be administered to emerging adults and parents who were living in separate locations. Participants were recruited through faculty's announcement of the study in undergraduate and graduate courses. Professors at the various universities were provided with a handout to give to their students that had a brief explanation of the study and directions for accessing the online survey. Interested students then accessed the study Web site with a location-specific recruitment code. Informed consent was obtained online, and only after consent was given could the participants begin the questionnaires. Each participant was asked to complete a survey battery of 448 items. Sections of the survey addressed topic areas such as background information, family-of-origin experiences, self-perceptions, personality traits, values, risk behaviors, dating behaviors, prosocial behaviors, and religiosity. Approximately 5\% of emerging adult participants were offered monetary compensation for their own participation, with the majority receiving extra credit or course credit for participating. For the majority of emerging adults, parental participation resulted in monetary compensation for the emerging adult (e.g., \$10-\$20 gift certificates). 
Approximately $30 \%$ of students were offered extra or course credit for their parents' participation.

After participants completed the personal information, they had the option to send an invitation to their parents to participate in the study via e-mail. The e-mail invitation included an assigned password and a link to the parents' version of the questionnaire. The parents were directed to click on the link and enter the password. Once the password was entered, an informed consent form appeared, and parents then followed the same protocol as the children. If parents did not have e-mail addresses, mailing addresses were obtained, and questionnaires were mailed to them with self-addressed, prepaid envelopes (this occurred in less than $1 \%$ of the cases). Parents completed a shorter battery of 280 items similar to the ones their children completed.

\section{Measures}

Adult status. As an assessment of adult status, emerging adults were asked the following question: "Do you think that you have reached adulthood?" Response options included yes, no, or in some respects yes, in some respects no. Parents were asked "Do you think that your child has reached adulthood?" Parent response options also included yes, no, or in some respects yes, in some respects no. This method of adult-status classification has been used elsewhere and has demonstrated adequate face validity (e.g., Arnett, 1998, 2003; Nelson, \& Barry, 2005). Indeed, Nelson and Barry (2005) found that this single item adequately differentiated individuals who answered "yes" from those who answered either "no" or "in some respects yes, in some respects no" (the latter two responses were collapsed together) on important developmental features such as identity achievement, depression, and participation in risk behaviors (e.g., illegal drug use).

Criteria for adulthood. As an assessment of criteria for adulthood, all participants (children and parents) were presented with a list of possible criteria for adulthood (e.g., "finishing education," "avoid drunk driving," "purchasing a house"; Arnett, 1998, 2003). Participants were asked to "[i]ndicate whether or not YOU believe the following are necessary for adulthood." They could respond "yes" (i.e., necessary for adulthood) or "no" (i.e., not necessary for adulthood) to each item. They were then presented the same list and asked to "give your opinion on the importance of each of the following in determining whether or not a person has reached adulthood." They could rate each item on a scale of 1 (not at all important) to 4 (very important). This measure has been commonly used in this population (e.g., Arnett, 1998, 2003; Barry \& Nelson, 2005; Cheah \& Nelson, 2004; Nelson \& Barry, 2005), and the way in which the criteria were grouped into categories in the current study was based upon previous research that demonstrated the internal validity of the subscales (Badger et al., 2006). Table 1 contains the items from each subscale. The subscales included role transitions $(\alpha=.80, .80$, and .79 , for emerging adults, mothers, and fathers, respectively), norm compliance $(\alpha=.82, .85$, and .85$)$, biological/age-related tran- sitions $(\alpha=.79, .79$, and .78), family capacities $(\alpha=.91$, .92 , and .92), and relational maturity ( $\alpha=.57, .67$, and .60).

\section{Results}

Consistent with past research on emerging adults' criteria for adulthood (e.g., Arnett, 1998, 2003; Nelson, 2003), the data were first examined descriptively (by item) in an attempt to understand patterns of responses on criteria necessary for adulthood and importance of criteria for adulthood across the three respondents (emerging adult, father, mother). Next, individual items were organized into subscales, and given the dependency of the data, hierarchical linear modeling was used to compare the importance of criteria for adulthood as a function of respondent and gender of the child.

\section{Perceived Adult Status}

To determine whether parents believed their children had attained adult status, responses to the question "Do you think that your child has reached adulthood?" were examined. For comparison, responses by emerging adults to the same question were also examined. Results showed that $16 \%$ of the emerging adults indicated "yes," $13 \%$ answered "no," and 72\% answered "in some ways yes, in some ways no." For fathers, $19 \%$ indicated "yes," 16\% answered "no," and $65 \%$ answered "in some ways yes, in some ways no." For mothers, $16 \%$ indicated "yes," $16 \%$ answered "no," and $68 \%$ answered "in some ways yes, in some ways no."

\section{Criteria Necessary for Adulthood}

To investigate the criteria that parents, compared to their children, deemed necessary for adulthood, responses to the question "Is this criterion necessary for adulthood?" were examined for emerging adults, fathers, and mothers, respectively. The four criteria that received the most "yes" responses from emerging-adult children included the following: (a) "Accept responsibility for the consequences of your actions," (b) "Establish relationship with parents as an equal adult," (c) "Financially independent from parents," and (d) "Decided on beliefs/values independently of parents/other influences." For fathers, the four criteria that received the most "yes" responses included the following: (a) "Accept responsibility for the consequences of your actions," (b) "Avoid committing petty crimes like vandalism and shoplifting," (c) "Avoid drunk driving," and (d) "Become less self-oriented, develop greater consideration for others." For mothers, the four criteria that received the most "yes" responses included the following: (a) "Accept responsibility for the consequences of your actions," (b) "Avoid drunk driving," (c) "Avoid committing petty crimes like vandalism and shoplifting," and (d) "Become less self-oriented, develop greater consideration for others."

\section{Importance of Criteria for Adulthood}

As an investigation of how important parents, compared with their children, considered each criterion for adulthood, 
Table 1

List of Possible Criteria for Adulthood

\begin{tabular}{|c|c|}
\hline Category & Criterion \\
\hline Role transitions & $\begin{array}{l}\text { Financially independent from parents } \\
\text { No longer living in parents' household } \\
\text { Finish education } \\
\text { Married } \\
\text { Have at least one child } \\
\text { Settle into a long-term career } \\
\text { Purchase a house }\end{array}$ \\
\hline Norm compliance & $\begin{array}{l}\text { Avoid becoming drunk } \\
\text { Avoid drunk driving } \\
\text { Avoid illegal drugs } \\
\text { Have no more than one sexual partner } \\
\text { Avoid committing petty crimes like vandalism and shoplifting } \\
\text { Drive safely and close to the speed limit } \\
\text { Avoid use of profanity/vulgar language } \\
\text { Use contraception if sexually active and not trying to conceive } \\
\text { a child }\end{array}$ \\
\hline Biological/age transitions & $\begin{array}{l}\text { Reach age } 18 \\
\text { Reach age } 21 \\
\text { Grow to full height } \\
\text { If a woman, become biologically capable of bearing children } \\
\text { If a man, become biologically capable of fathering children } \\
\text { Have obtained license and can drive an automobile } \\
\text { Have had sexual intercourse } \\
\text { Allowed to drink alcohol } \\
\text { Allowed to smoke cigarettes }\end{array}$ \\
\hline Family capacities & $\begin{array}{l}\text { If a woman, become capable of supporting a family financially } \\
\text { If a man, become capable of caring for children } \\
\text { If a woman, become capable of caring for children } \\
\text { If a man, become capable of running a household } \\
\text { If a man, become capable of keeping family physically safe } \\
\text { If a woman, become capable of keeping family physically safe }\end{array}$ \\
\hline Relational maturity & $\begin{array}{l}\text { Accept responsibility for the consequences of your actions } \\
\text { Establish a relationship with parents as an equal adult } \\
\text { Learn always to have good control of your emotions } \\
\text { Become less self-oriented, develop greater consideration for } \\
\text { others }\end{array}$ \\
\hline
\end{tabular}

responses to the question "How important is this criterion for adulthood?" were examined for emerging adults, fathers, and mothers, respectively. According to emerging adults, the four most important criteria were (a) "Accept responsibility for the consequences of your actions," (b) "Avoid drunk driving," (c) "Avoid committing petty crimes like vandalism and shoplifting," and (d) "Financially independent from parents." According to fathers and mothers, the four most important criteria were (a) "Accept responsibility for the consequences of your actions," (b) "Avoid committing petty crimes like vandalism and shoplifting," (c) "Avoid drunk driving," and (d) "Become less self-oriented, develop greater consideration for others."

\section{Parent-Child Comparisons}

As an examination of the importance that parents versus their children placed on criteria for adulthood, individual items were organized into five subscales. As noted previously, they included Role Transitions (e.g., "married"),
Norm Compliance (e.g., "avoid becoming drunk"), Biological/Age Transitions (e.g., "grow to full height"), Family Capacities (e.g., "if a woman, become capable of supporting a family financially"), and Relational Maturity (e.g., "become less self-oriented, develop greater consideration for others"). In Table 2, the means and standard deviations are presented in order of importance for young men, young women, fathers of young men, fathers of young women, mothers of young men, and mothers of young women.

Given the dependent nature of the data, hierarchical linear modeling (with the MIXED procedure in SPSS) was used to examine differences in the importance placed on the various criteria for adulthood by emerging adults, fathers and mothers (see Table 3). This approach was used to nest individual respondents (emerging adults, fathers, and mothers) within families. For all analyses, independent variables were respondent and child gender. Dependent variables were the five criteria subscales. 
Order of Importance of the Criteria for Adulthood for Emerging Adults, Fathers, and Mothers

\begin{tabular}{|c|c|c|c|c|c|c|c|c|c|c|}
\hline \multirow[b]{2}{*}{ Respondent } & \multicolumn{2}{|c|}{$\begin{array}{c}\text { Relational } \\
\text { maturity }\end{array}$} & \multicolumn{2}{|c|}{$\begin{array}{l}\text { Family } \\
\text { capacities }\end{array}$} & \multicolumn{2}{|c|}{$\begin{array}{l}\text { Norm } \\
\text { compliance }\end{array}$} & \multicolumn{2}{|c|}{$\begin{array}{c}\text { Role } \\
\text { transitions }\end{array}$} & \multicolumn{2}{|c|}{$\begin{array}{c}\text { Biological/age } \\
\text { transitions }\end{array}$} \\
\hline & $M$ & $S D$ & $M$ & $S D$ & $M$ & $S D$ & $M$ & $S D$ & $M$ & $S D$ \\
\hline Young men & 3.36 & 0.43 & 3.01 & 0.77 & 2.69 & 0.63 & 2.49 & 0.55 & 1.76 & 0.51 \\
\hline Young women & 3.44 & 0.44 & 3.01 & 0.68 & 2.93 & 0.67 & 2.50 & 0.49 & 1.65 & 0.55 \\
\hline Fathers of young men & 3.49 & 0.43 & 3.19 & 0.58 & 3.07 & 0.70 & 2.34 & 0.47 & 1.59 & 0.53 \\
\hline Fathers of young women & 3.37 & 0.41 & 3.27 & 0.57 & 3.03 & 0.71 & 2.28 & 0.53 & 1.51 & 0.41 \\
\hline Mothers of young men & 3.58 & 0.42 & 3.45 & 0.52 & 3.15 & 0.73 & 2.34 & 0.50 & 1.56 & 0.50 \\
\hline Mothers of young women & 3.50 & 0.42 & 3.46 & 0.53 & 3.22 & 0.68 & 2.35 & 0.53 & 1.54 & 0.49 \\
\hline
\end{tabular}

Results revealed a significant main effect of gender for norm compliance, $F(1,883.45)=8.58, p<.01$, and biological/age transitions, $F(1,882.12)=4.45, p<.05$. On average, respondents rated importance of norm compliance higher for young women than young men, and importance of biological/age transitions as more important for young men than young women.

Results revealed a significant main effect of respondent for role transitions, $F(2,606.89)=11.38, p<.001$; norm compliance, $F(2,647.96)=112.28, p<.001$; biological $/$ age transitions, $F(2,598.91)=10.12, p<.001$; family capacities, $F(2,596.03)=5.10, p<.01$; and relational maturity, $F(2,611.25)=8.31, p<.001$. Follow-up analyses, using Fisher's least significant difference test, revealed that emerging adults rated role transitions as more important than did both fathers and mothers, who did not differ from one another; emerging adults rated norm compliance as less important than did fathers and mothers, and fathers rated norm compliance as less important than did mothers; emerging adults rated biological/age transitions as more important than did fathers and mothers, who did not differ from one another; emerging adults and fathers rated family capacities as less important than did mothers; and emerging adults and fathers rated relational maturity as less important than did mothers.

Results revealed a significant interaction for norm compliance, $F(2,647.96)=3.64, p<.05$, and relational maturity, $F(2,611.25)=5.35, p<.01$. Because of hypothesized differences as a function of gender of the child and gender of the parent, contrast follow-ups were used. Three contrasts were conducted for each interaction, the first comparing male and female emerging adults, the second comparing fathers of emerging adult men and fathers of emerging adult women, and the third comparing mothers of emerging adult men and mothers of emerging adult women. For norm compliance, only the first contrast revealed significant differences, with emerging adult women $(M=2.93)$ rating norm compliance as more important than did emerging adult men $(M=2.69)$, $t(383)=4.00, p<.01$. For relational maturity, the first two contrasts revealed significant differences, with emerging adult women $(M=3.44)$ rating relational maturity as more important than did emerging adult men $(M=3.36), t(383)=-1.94, p<.05$, and fathers of emerging adult men $(M=3.49)$ rating relational maturity as more important than did fathers of emerging adult women $(M=3.37), t(276)=2.35, p<.05$.

\section{Discussion}

The purpose of this study was to assess whether parents considered their 18- to 25-year-old children to be adults as well as to examine the criteria parents considered necessary and important for their children to achieve in order to be considered adults. Furthermore, differences in criteria for adulthood were explored as a function of the gender of the parent and the gender of the child. Results revealed that (a) most parents did not see their children as adolescents, yet they did not view them fully as adults either; (b) although

Table 3

Differences Between Emerging Adults', Fathers', and Mothers' Criteria for Adulthood by Gender of Child

\begin{tabular}{|c|c|c|c|c|c|c|c|c|c|c|c|c|}
\hline \multirow[b]{2}{*}{ Criterion } & \multicolumn{2}{|c|}{ Young men } & \multicolumn{2}{|c|}{$\begin{array}{c}\text { Young } \\
\text { women }\end{array}$} & \multirow[b]{2}{*}{$F$} & \multicolumn{2}{|c|}{$\begin{array}{l}\text { Emerging } \\
\text { adult }\end{array}$} & \multicolumn{2}{|c|}{ Father } & \multicolumn{2}{|c|}{ Mother } & \multirow[b]{2}{*}{$F$} \\
\hline & $M$ & $S D$ & $M$ & $S D$ & & $M$ & $S D$ & $M$ & $S D$ & $M$ & $S D$ & \\
\hline Role transitions & 2.39 & 0.52 & 2.38 & 0.52 & 0.15 & $2.49 \mathrm{a}$ & 0.51 & $2.31_{b}$ & 0.51 & $2.34_{b}$ & 0.52 & $11.38^{* * * * *}$ \\
\hline Norm compliance & 3.11 & 0.63 & 3.22 & 0.67 & $3.64^{*}$ & $2.81_{\mathrm{a}}^{\mathrm{a}}$ & 0.60 & $3.23_{\mathrm{b}}^{\mathrm{D}}$ & 0.59 & $3.45_{\mathrm{c}}^{\mathrm{D}}$ & 0.50 & $112.28^{* * * * k}$ \\
\hline Biological/age transitions & 1.64 & 0.51 & 1.57 & 0.55 & $4.45^{*}$ & $1.71_{\mathrm{a}}^{\mathrm{a}}$ & 0.58 & $1.55_{\mathrm{b}}^{\circ}$ & 0.52 & $1.55_{\mathrm{b}}$ & 0.46 & $10.12^{* * * *}$ \\
\hline Family capacities & 3.07 & 0.77 & 3.08 & 0.68 & 0.05 & $3.01_{\mathrm{a}}$ & 0.71 & $3.05_{\mathrm{a}}$ & 0.72 & $3.18_{\mathrm{b}}$ & 0.73 & $5.10^{* * *}$ \\
\hline Relational maturity & 3.47 & 0.43 & 3.44 & 0.44 & 1.66 & $3.40_{\mathrm{a}}^{\mathrm{a}}$ & 0.46 & $3.43_{\mathrm{a}}^{\mathrm{a}}$ & 0.40 & $3.54_{\mathrm{b}}^{\mathrm{D}}$ & 0.42 & $8.31^{* * * *}$ \\
\hline
\end{tabular}

Note. Means in the same row with differing subscript letters are significantly different from one another based on least significant difference post-hoc analyses. Columns labeled "young men" and "young women" represent emerging adults', fathers', and mothers' combined perceptions of differences between young men and young women.

$p<.05 .^{* * *} p<.01 .{ }_{* * *}^{*} p<.001$. 
there was some consensus between emerging-adult children and their parents, there was also considerable disagreement in the emphasis they placed on various criteria for adulthood; and (c) the gender of the parent and the gender of the child played a role in the criteria their parents deemed important for adulthood. Each of these findings has important implications for parent-child relationships during emerging adulthood as well as potential application in therapy and for future research.

\section{Criteria for Adulthood}

One purpose of the current study was to examine generational differences in criteria for adulthood. Findings suggested that the majority of parents viewed their children as an adult in some ways and not in others. This finding is consistent with the theory of emerging adulthood as well as past research suggesting that most emerging adults consider themselves to be somewhere in between an adolescent and an adult (Arnett, 2000, 2006; Nelson \& Barry, 2005) and extends existing research by suggesting that there is generational congruence in viewing and treating emerging adulthood as a distinct period between adolescence and adulthood. Indeed, it is possible that parents' own views of the criteria for adulthood and their perceived achievement of adulthood criteria are part of the value system they attempt to teach their children, which may play an important role in determining the criteria emerging adults adopt for themselves to be considered adults.

To examine this question further, we explored whether parents and their emerging adult child identified similar criteria as being necessary for adulthood. Findings showed that parents' criteria for adulthood were similar to emerging adults' criteria (i.e., both viewed aspects of relational maturity as the most essential criteria for adulthood rather than events such as marriage). The consensus of relational maturity being so important in preparing for adulthood has both methodological and practical implications. First, its status as the most important domain to young people and parents shows that this construct is capturing something of consequence. It appears to possess both face and internal validity and, therefore, should be a useful tool in future research. Second, past research has attempted to separate criteria for adulthood that focus on independence from those that focus on interdependence (e.g., Arnett, 2003; Nelson \& Barry, 2005). However, these results support those of Badger et al. (2006) in suggesting that the processes involved in becoming an independent person are simultaneously preparing one for relationships.

Despite consensus that relational maturity is the most important set of criteria, emerging adults and their parents appeared to disagree on the magnitude of importance of some of the other critical issues related to adulthood. Specifically, both mothers and fathers rated norm compliance as more important for adulthood than did emerging adults. Furthermore, emerging adults rated family capacities higher in importance than norm compliance and considered role transitions and biological/age transitions to be more impor- tant than did either of their parents. Taken together, these findings suggest areas of significant congruence as well as meaningful differences between children's and parents' criteria for adulthood.

\section{Gender Differences}

The current study also explored differences in criteria for adulthood as a function of gender of the parent and gender of the child. Results showed that mothers and fathers differed in the extent to which they rated various criteria as important for their child, including norm compliance (fathers considered it more important than mothers), family capacities (mothers rated it as more important than fathers), and relational maturity (mothers endorsed it more than fathers). These differences may have ramifications for the marital relationship. Studies have shown that differences in approaches to parenting are related to marital conflict. For example, there is a growing interest in the notion of coparenting, which reflects the need for parents to "mesh their goals, styles, and strategies to provide consistent and coherent expectations and consequences for their children" (Grych, 2002, p. 219). The inability to communicate, work together, and settle differences regarding parenting appears to be related to both effective co-parenting and the state of the marital relationship (e.g., see Grych, 2002, for a review). Given that launching children is a major developmental task for this time period, it stands to reason that different approaches on how to accomplish this task may have salient effects on a relationship. Therefore, therapists should not overlook this as a potential source of conflict in the marriage. To facilitate this, future research should examine whether it is disagreement in general or whether the magnitude of the discrepancy in certain key domains is what creates the potential for problems between partners.

In addition, criteria differed as a function of the gender of the child. Findings were consistent with gender differences in parental socialization, in that parents socialize their daughters to be more care oriented and are more protective of their daughters (Maccoby, 1995); thus, it is not surprising that emerging adult women considered relational maturity and norm compliance as more important than did emerging adult men. In addition, fathers of sons rated relational maturity to be more important than did fathers of daughters. It is possible that given the tendency for women to focus on relationships (Gilligan, 1982), these criteria were especially salient for fathers of sons because sons may be perceived as being less adept in relational maturity. Taken together, these findings are consistent with past research suggesting the importance of researchers considering gender when examining the parent-child relationship (Fagot, 1995) and highlight the importance of considering the different expectations that are held for adulthood as a function of gender.

\section{Implications for Future Research}

Findings from this study may have a number of implications for future research and clinical practice. First, differ- 
ences between parents and emerging adults may have an impact on the quality of the parent-child relationship. Although little research has been conducted on parent-child relationships during emerging adulthood, a lifespan perspective of parenting suggests that parents continue to be important factors in their adult children's lives (Zarit \& Eggebeen, 2002). However, differences in parent-child values regarding criteria for adulthood may result in an increase in parent-child conflict during the emerging adult years. Indeed, research suggests that family conflict increases when young people do not conform with parental expectations for adulthood (Schnaiberg \& Goldenberg, 1989) and decreases as young people achieve childendorsed criteria for adulthood (Shulman \& Ben-Artzi, 2003). In the future, researchers should examine the possibility that discrepancies between parent and emerging adult criteria for adulthood may place a strain on their relationship. Furthermore, better understanding of the disagreement between parents and children on these issues, and the potential antecedents and outcomes of these differences, would help to provide a starting point in family therapy that involves a child between the ages of 18 and 25 .

Conversely, it would also seem important to examine the role that the parent-child relationship may have on the criteria that the children deem important for adulthood. Given that a positive parent-child relationship tends to foster internalization of values (Grusec \& Goodnow, 1994), it may be expected that children who have a positive relationship with their parents will have internalized the values of their parents and therefore hold views that are more similar to their parents' regarding expectations for adult status. Parenting styles (e.g., authoritative, authoritarian, permissive), both during childhood and adolescence as well as during emerging adulthood, may also play a role in both the quality of the parent-child relationship and the criteria young people deem important for adulthood. Taken together, several aspects of the parent-child relationship need to be explored as predictors of discrepancies between parents' and emerging adult children's criteria for adulthood as well as the impact of incongruence on the parent-child relationship.

Next, it seems important to better understand the causal directions in the relationship between parent criteria for adulthood and their children's behavior during emerging adulthood. For example, it may be that parents, like their children, view emerging adulthood as a period of transition and experimentation, after which parents expect their children to comply more fully with societal norms. On the other hand, parents may be responding to what they possibly perceive to be excessive disregard for societal norms (e.g., binge drinking, experimentation with drugs) on the part of their child and, therefore, emphasize norm compliance in an attempt to curtail these types of behavior. Future work should focus on how parents' criteria for adulthood differ as a function of the emerging adults' behaviors and personality.

Finally, future work should examine the developmental changes that occur in the criteria individuals have for adulthood. It is possible that the criteria one deems important for adulthood changes at some point in the lifespan. For example, it may be that an individual's view differs once he or she becomes an adult. Past research suggests that although emerging adults do not list being a parent as an important criteria for adulthood, nearly all emerging adults who are already parents list parenthood as the marker that made them an adult (Arnett, 2000). In other words, one's own experiences (e.g., becoming a parent) may change one's perception of how important certain criteria are. This change in perspective may even occur several times across the lifespan, including several times during emerging adulthood. Although several cross-sectional approaches have been undertaken to examine these differences at various points across the lifespan (e.g., Arnett, 2001; Bangerter et al., 2001), longitudinal research is needed to determine how emerging adults' criteria for adulthood change as they age and experience many of the markers they considered important for adulthood.

\section{Limitations and Conclusions}

This study was not without limitations. First, the sample consisted of college students and therefore may not be generalizable to a nonstudent population. There is still relatively little that is known about individual differences in the "forgotten half" (young people who do not attend college after high school; William T. Grant Foundation Commission on Work, Family, and Citizenship, 1988) on issues such as criteria for adulthood, attitudes and beliefs about marriage and family life, identity formation, and parentchild relationships. Thus, the need to examine this population cannot be underscored enough. However, the results of the current study provide an important foundation from which future work can be conducted examining parentchild relationships with noncollege populations. Furthermore, given that two thirds of young people in the United States enter college the year following high school (National Center for Education Statistics, 2002, Table 20-2), findings from the present study are relevant for a good portion of young people in the United States.

Also related to the study of college students was our use of extra credit for participant compensation. The use of extra credit for compensation may have resulted in a select sample of college students in terms of academic achievement (Padilla-Walker, Zamboanga, Thompson, \& Schmersal, 2005), but there is little reason to believe that these individuals would differ substantially on their criteria for adulthood. However, it is possible that emerging adults who invited their parents to participate had closer relationships with their parents, which might account for the similarity in many criteria found in the current study. Although we could not directly assess this possibility, future research should explore more diverse populations to determine whether similarity between parents' and children's criteria for adulthood varies as a function of the quality of the parent-child relationship.

Second, the use of Internet questionnaires could be seen as a limitation. Findings related to the limitations and 
strengths of Internet surveys are mixed, with some researchers arguing that using Internet surveys potentially eliminates participants who do not have access to the Internet and results in low response rates due to respondents' deletion of nonrecognizable e-mails (Tuten, Urban, \& Bosnjak, 2002). However, given research suggesting that virtually $100 \%$ of college students have access to the Internet (Harris Interactive, 2001) and research suggesting that the benefits of using Internet based surveys may improve sampling and reduce missing data while maintaining a covariance structure similar to that of paper-and-pencil measures of the same variables (Stanton, 1998), it is possible that the use of Internet surveys is equally effective, if not more effective, than typical paper-and-pencil measures in this population.

Third, the sample lacked ethnic and socioeconomic diversity. Arnett (2003) found important similarities and differences in the criteria endorsed by young people of different ethnic subgroups in the United States, and it would therefore be interesting to examine whether the areas in which young people differ from the larger culture are on criteria in which they are more similar to their parents. Research by Cheah and Nelson (2004) underscored the importance of examining acculturation in the transition to adulthood. Specifically, the extent to which emerging adults identify more with the larger culture or their culture of origin affects the criteria they deem important for adulthood. If children endorse criteria deemed less important to their parents because of cultural values, this may have serious ramifications for the parent-child relationship. Taken together, there is a real need to examine these issues in more diverse populations.

On a related note, this study does not take into account the diversity that exists within families. For example, future work needs to take into account the diversity of various structural and sociodemographic factors of families. Furthermore, researchers should examine how family events (e.g., death, illness, divorce, and remarriage) may influence the processes of endorsing and achieving criteria for adulthood as well as how parent-child and spousal relationships are affected by congruence, or lack thereof, in the beliefs concerning criteria for adulthood.

Despite these limitations, this study makes several unique contributions. Most notably, it is one of the first studies examining criteria for adulthood to include data from both parents and children. Previous studies have either assessed young people's criteria or adults' criteria, but this study provides insight into the parent-child relationship by simultaneously assessing the views of parents and children. The findings are important because they reflect areas of agreement between parents and children but also areas of disagreement. The differences revealed in this study may serve as a starting point for subsequent work, including both research and practice, examining the impact that discrepancies in beliefs and attitudes (e.g., criteria for adulthood) concerning the transition to adulthood may have on young people's development, the parent-child relationship, and the marital relationship.

\section{References}

Arnett, J. J. (1994). Are college students adults? Their conceptions of the transition to adulthood. Journal of Adult Development, 1 , $154-168$.

Arnett, J. J. (1998). Learning to stand alone: The contemporary American transition to adulthood in cultural and historical context. Human Development, 41, 295-315.

Arnett, J. J. (2000). Emerging adulthood: A theory of development from the late teens through the twenties. American Psychologist, 55, 469-480.

Arnett, J. J. (2001). Conceptions of the transition to adulthood: Perspectives from adolescence through midlife. Journal of Adult Development, 8, 133-143.

Arnett, J. J. (2003). Conceptions of the transition to adulthood among emerging adults in American ethnic groups. New Directions in Child and Adolescent Development, 100, 63-75.

Arnett, J. J. (2006). Emerging adulthood: Understanding the new way of coming of age. In J. J. Arnett \& J. L. Tanner (Eds.), Emerging adults in America: Coming of age in the 21st century (pp. 3-20). Washington, DC: American Psychological Association.

Badger, S., Nelson, L. J., \& Barry, C. M. (2006). Perceptions of the transition to adulthood among Chinese and American emerging adults. International Journal of Behavioral Development, 30 , 84-93.

Bangerter, A., Grob, A., \& Krings, F. (2001). Personal goals at age 25 in three generations of the twentieth century: Young adulthood in historical context. Swiss Journal of Psychology, 60, 59-64.

Barry, C. M., \& Nelson, L. J. (2005). The role of religion in the transition to adulthood for young emerging adults. Journal of Youth and Adolescence, 34, 245-255.

Bockneck, G. (1986). The young adult: Development after adolescence. New York: Gardner Press.

Cheah, C. S. L., \& Nelson, L. J. (2004). The role of acculturation in the emerging adulthood of Aboriginal college students. International Journal of Behavioral Development, 28, 495-507.

Côté, J. E. (2000). Arrested adulthood: The changing nature of maturity and identity. New York: New York University Press.

Erikson, E. H. (1968). Identity: Youth and crisis. New York: Norton.

Facio, A., \& Micocci, F. (2003). Emerging adulthood in Argentina. New Directions in Child and Adolescent Development, 100, 21-31.

Fagot, B. I. (1995). Parenting boys and girls. In M. H. Bornstein, (Ed.), Handbook of parenting: Vol. 1. Children and parenting (pp. 163-183). Mahwah, NJ: Erlbaum.

Gilligan, C. F. (1982). In a different voice. Cambridge, MA: Harvard University Press.

Grusec, J. E., \& Goodnow, J. J. (1994). The impact of parental discipline methods on the child's internalization of values: A reconceptualization of current points of view. Developmental Psychology, 34, 4-19.

Grych, J. H. (2002). Marital relationships and parenting. In M. H. Bornstein (Ed.), Handbook of parenting: Vol. 4. Social conditions and applied parenting (pp. 203-225). Mahwah, NJ: Erlbaum.

Harris Interactive. (2001). Presenting: The class of 2001. Retrieved September 1, 2006, from http://www.harrisinteractive.com/news/ allnewsbydate. asp?NewsID $=292$

Hosley, C. A., \& Montemayor, R. (1997). Fathers and adolescents. In M. E. Lamb (Ed.), The role of the father in child development (3rd ed., pp. 162-178). New York: Wiley. 
Keniston, K. (1971). Youth and dissent: The rise of a new opposition. New York: Harcourt Brace Jovanovich.

Lamb, M. E., Hwang, C. P., Ketterlinus, R. D., \& Fracasso, M. P. (1999). Parent-child relationships: Development in the context of the family. In M. H. Bornstein \& M. E. Lamb (Eds.), Developmental psychology: An advanced textbook (pp. 411-450). Mahwah, NJ: Erlbaum.

Maccoby, E. E. (1995). The two sexes and their social systems. In P. Moen, G. H. Elder, \& K. Luscher (Eds.), Examining lives in context (pp. 347-364). Washington, DC: American Psychological Association.

Mayseless, O., \& Scharf, M. (2003). What does it mean to be an adult? The Israeli Experience. New Directions for Child and Adolescent Development, 100, 5-20.

National Center for Education Statistics. (2002). The condition of education 2002. Retrieved February 15, 2003, from http:// www.nces.ed.gov/pubs2002/2002025.pdf

Nelson, L. J. (2003). Rites of passage in emerging adulthood: Perspectives of young Mormons. New Directions for Child and Adolescent Development, 100, 33-49.

Nelson, L. J., Badger, S., \& Wu, B. (2004). The influence of culture in emerging adulthood: Perspectives of Chinese college students. International Journal of Behavioral Development, 28, 26-36.

Nelson, L. J., \& Barry, C. M. (2005). Distinguishing features of emerging adulthood: The role of self-classification as an adult. Journal of Adolescent Research, 20, 242-262.
Padilla-Walker, L. M., Zamboanga, B. L., Thompson, R. A., \& Schmersal, L. A. (2005). Extra credit as incentive for voluntary research participation. Teaching of Psychology, 32, 150-153.

Schnaiberg, A., \& Goldenberg. S. (1989). From empty nest to crowded nest: The dynamics of incompletely launched young adults. Social Problems, 36, 251-269.

Shulman, S., \& Ben-Artzi, E. (2003). Age-related differences in the transition to adolescence to adulthood and links with family relationships. Journal of Adult Development, 10, 217-226.

Stanton, J. M. (1998). An empirical assessment of data collection using the Internet. Personnel Psychology, 51, 709-725.

Tuten, T. L., Urban, D. J., \& Bosnjak, M. (2002). Internet surveys and data quality: A review. In B. Batinic, U. Reips, \& M. Bosnjak, (Eds.). Online social sciences (pp. 7-26). Ashland, OH: Hogrefe \& Huber.

William T. Grant Foundation Commission on Work, Family, and Citizenship. (1988). The forgotten half: Non-college-bound youth in America. Washington, DC: William T. Grant Foundation.

Zarit, S. H., \& Eggebeen, D. A. (2002). Parent-child relationships in adulthood and old age. In M. H. Bornstein (Ed.). Handbook of parenting (2nd ed., pp. 135-164). Mahwah, NJ: Erlbaum.

Received June 4, 2006 Revision received February 2, 2007 Accepted February 3, 2007

\section{ORDER FORM}

Start my 2008 subscription to the Journal of Family

Psychology! ISSN: 0893-3200

\section{\$57.00, APA Member/Affiliate \\ \$126.00, INDIVIDUAL NONMEMBER \$400.00, INSTITUTION \\ In DC add 5.75\% / In MD add 5\% sales tax} Total Amount Enclosed

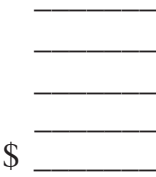

Subscription orders must be prepaid. (Subscriptions are on a calendar year basis only.) Allow 4-6 weeks for delivery of the first issue. Call for international subscription rates.

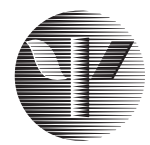

AMERICAN PSYCHOLOGICAL ASSOCIATION

\section{SEND THIS ORDER FORM TO:}

American Psychological Association Subscriptions

750 First Street, NE

Washington, DC 20002-4242

Or call 800-374-2721, fax 202-336-5568.

TDD/TTY 202-336-6123.

For subscription information, e-mail: subscriptions@apa.org
Check enclosed (make payable to APA)

Charge my: OVISA MasterCard OAmerican Express

Cardholder Name

Card No. Exp. Date

Signature (Required for Charge)

BILLING ADDRESS:

Street

$\begin{array}{ll}\text { City } & \text { State __ Zip } \\ \text { Daytime Phone _ـ } & \\ \text { E-mail } & \end{array}$

\section{MAIL TO:}

Name

Address

City State Zip

APA Member \# FAMA08 